\title{
Establishment on Evaluation Index System for Outside School Practical Teaching Base of Tourism Management Major
}

\author{
Hongyan Liu \\ College of Finance and Trade, Bohai University, Jinzhou, 121013, China \\ 47203209@qq.com
}

Keywords: tourism management major; outside school practical teaching base; evaluation index system; structure model

\begin{abstract}
Practical teaching is an effective way to consolidate theoretical knowledge and deepen theoretical understanding. The construction and evaluation of outside school practice teaching base is an important link to improve the quality of higher education. Through the comprehensive research literature on the evaluation of practical teaching base at home and abroad, according to the practical teaching of the characteristics of tourism management major and the construction of the comprehensive scientific evaluation index system. It consists of five first-level indexes, such as "Construction and management, Practice teaching, Conditions and facilities, Teaching effectiveness, other aspects", and six second-level indexes under each first-level index. The research results of this paper are the basic work of the evaluation of outside school practical teaching base, which is conducive to strengthening the management of practical teaching base, improving the effectiveness of outside school practical teaching, and improving the quality of talent training in tourism management major.
\end{abstract}

\section{Introduction}

Tourism management is a new subject that has emerged along with economic development. The tourism management major is oriented towards modern tourism. According to the development of the tourism industry, it cultivate the support for the party, adapts to the needs of the front line of production, management and service, and has high-tech applied professionals with comprehensive development of morality, intelligence, body and beauty. On the basis of basic theoretical knowledge and professional knowledge, students focus on the areas of tour guides, travel agencies, tourist attractions and tourist shopping stores, basic capacity and basic skills in practical work, good professional ethics and professionalism; master the theory and method of business management in modern tourism, take well charge of tourism enterprises and related industry management, senior talents and entrepreneurial talents in teaching and research. Tourism education needs to keep pace with the time and cultivate tourism talents who are suitable for the development of the industry.

Through practice, students will acquire perceptual knowledge, conduct skill training, improve overall quality, and cultivate innovative spirit. As a practical application subject, the tourism management major must have strong practical operation ability and ability to deal with emergencies. Therefore, practical teaching has an irreplaceable role. The practical teaching base is the main carrier for carrying out practical teaching, and it has the distinction between generalization and specialization. The practical teaching base in the generalized sense refers to the platform or place specially set up for practical teaching activities to improve the level of practical teaching and meet the needs of practical teaching, including the training bases of enterprise practical training bases, government departments and public institutions. The narrowed practical teaching base refers to the platform established for the practice of teaching activities in colleges and universities according to the policies or documents of the higher authorities. It enriches students' practical ability and comprehensive quality.

The cultivation of tourism talents in China is far behind the development of tourism. Students' satisfaction with this major is low, the wastage rate is serious, and the demand for tourism talents is 
misplaced, which has restricted the development of tourism and tourism education. The effect of practical teaching is related to the quality of talents training. The outside school practical teaching base is the best platform for cultivating applied tourism talents. Through the deep cooperation between universities and tourism enterprises, improving students' comprehensive professional ability not only meets the employment needs of tourism enterprises, but also saves the human resources costs of enterprises and improves the satisfaction of students. Therefore, the construction of outside school practical teaching base has solved the bottleneck factors affecting the training of tourism management major. Under the guidance of undergraduate teaching evaluation, many colleges and universities attach importance to improving the quality of teaching, emphasizing the important position of practical teaching in the cultivation of talents, increasing the ratio of practical teaching and the construction of outside school practical bases. Carrying out the evaluation of outside school practical teaching base is an important part of teaching evaluation, which is conducive to cultivating innovative talents and achieving talents training objectives; it is conducive to strengthening the management of practical teaching bases and realizing the scientific management process; it is conducive to giving full play to the enthusiasm of teachers and students in practical teaching bases. Improve the effectiveness of outside school practical teaching; it is conducive to universities and local scientific research institutions, as well as production and teaching department, carry out cooperation in production, learning and research projects, enhance the reputation of schools, and promote students' employment.

\section{Establishment Principles of Evaluation Index System}

The evaluation principles is the theory, criterion and request, which evaluation activities must follow. According to the understanding of the nature of evaluation and the characteristics of the outside school practical teaching base, referring to other relevant references, the following principles should be followed in constructing the evaluation index system:

(1) Systematic principle. The system is composed of several components that interact with each other and has an organic whole with specific functions. Therefore, the systemic principle is also called the integrality principle, and integrality is one of the most basic attributes or characteristics of the system. Systemic requirements have a global awareness and a integrality view, and all aspects of the object being evaluated are indivisible organic wholes. When establishing a comprehensive evaluation index system, we should consider the interconnection, interaction and mutual restraint between each index and the surrounding environment from the the point of system, and consider the overall operation law of the system. All indexes are the comprehensive reflection of the system characteristics.

(2) Scientific principle. Scientificity is the criterion for judging whether the thing conforms to objective facts. It is scientifically based and the principle of science is a universal principle. First of all, we must have scientific theories to guide, grasp the essence of the evaluation object, the basic concept is clear, and the logical structure is rigorous; then, the theory should be combined with the reality, and the index system should be established under the guidance of the theory; finally, the scientific evaluation standard, clearer it is, more concise it is, and more realistic the description of the objective actual abstraction is, and the stronger the science is.

(3) Dynamic principle. The overall interrelationship is manifested in the dynamic condition. The system, connection, and regularity that exist in reality are changing, and the unchanging things do not exist. The society is a large system of dynamic development and change. The evaluation index of the outside school practical teaching base also changes with the development of the economy and society. The construction of the index system must consider this change and adjust the index system in time to improve the accuracy of the evaluation results.

(4) Comparability principle. Including horizontal comparability and vertical comparability, horizontal comparability refers to the comparison between different indexes in the same period; vertical comparability refers to the same index compared in different periods. When establishing the evaluation index system, it is necessary to pay attention to the statistical range of the index and the horizontal and vertical comparable ratios of the accounting methods. Statistical caliber refers to the 
standard used in statistical data, including statistical methods and statistical scope; accounting method is the method used for continuous, systematic and comprehensive reflection and supervision of index.

(5) Practicality principles. The selected evaluation index should not only meet the purpose of the comprehensive evaluation, but should also be supported by data. In the evaluation process, the accuracy and reliability of the data should be controlled. The data corresponding to the evaluation index must be accurate and the data source must be reliable. If the data corresponding to the evaluation indexes are not easy to collect, the difficulty and cost of the evaluation work are increased, and sometimes it is even not to be evaluated. At the same time, there is the method with standardization and standardizing the collected index data.

\section{Structure Model of Evaluation Index System}

The general method of constructing the index system is to sort out the collected data and then measure it according to the scale. It should use the method of logical deduction and the facts as the basis, and combine the subjective and objective factors to analyze and evaluate. To establish the evaluation index system, the actual problem should be decomposed into several factors. The factors are divided into several groups according to different attributes. The hierarchical structure can be divided into the top layer, the middle layer and the bottom layer. The top layer is also called the target layer, which represents the overall goal of the system; the middle layer is also called the criterion layer, which represents the intermediate link to achieve the overall goal. There may be multiple layers according to the size and complexity of the problem scale; the bottom layer is also called the solution layer. Indicates the measure, decision, or plan to be used to achieve the goal. Referring to the relevant references, the evaluation system structure of the outside school practical teaching base tourism management major constructed in this paper is shown in Fig.1.

\section{Brief Description of Evaluation Index System}

A brief description of the indexes included in the evaluation index architecture model shown in Fig. 1 is as follows:

(1) Construction and management, including six indexes: First, Cooperation way, the way schools and tourism companies jointly fund to construct, the school has more autonomy. Separately funded by tourism companies, outside school practice will be restricted by enterprises; Second, Construction planning, the construction of outside school practical base is a relatively complex project that requires overall planning. If there is no planning, the construction is very arbitrary, and the function will be flawed; Third, Adaptation level, adaptation level includes graduate students, undergraduates and vocational education students. If there are more adaptation levels, the future development space will be larger; Fourth, The utilization degree can also be expressed in terms of utilization, that is, the workload of the practical teaching base. If the workload is small and it is rest for a long time, it will not be fully effective; Fifth, Funds input, including construction funds and maintenance funds, and the stable source of funding is the guarantee for the normal operation of the practical teaching base; Sixth, Rules and regulations, detailed base management rules and regulations can ensure the orderly development of teaching and scientific research. If the rules and regulations are not complete, it will be in confusion.

(2) Practice teaching, including six indexes: First, Teaching plan, practical teaching and theoretical teaching is the same, which must have strict teaching plan, and follow the teaching plan, in order to ensure that the effect of practical teaching; Second, Teaching program, according to teaching plan, making practical teaching file content in outline form, including teaching purpose, teaching requirement and teaching content; Third, Teaching evaluation, through assessment, further consolidate their student mastery of what they learn, understand students' flexible application of knowledge ability to solve practical problems, and promote students' practical ability to improve; Fourth, Teaching material construction, in the process of practical teaching, lack of clear guidance, teaching material is relatively backward, in order to improve education quality, we must strengthen 
the construction of teaching material; Fifth, Teaching guidance, guidance ask teachers to be responsible, concern about the students, emphasis on theory and practice, carefully marking practice report, strict examine and evaluate results; Sixth, Teaching guarantee, with a variety of measures to ensure the quality of teaching practice, and strengthen the practice of teaching management, establish the practical teaching security system.

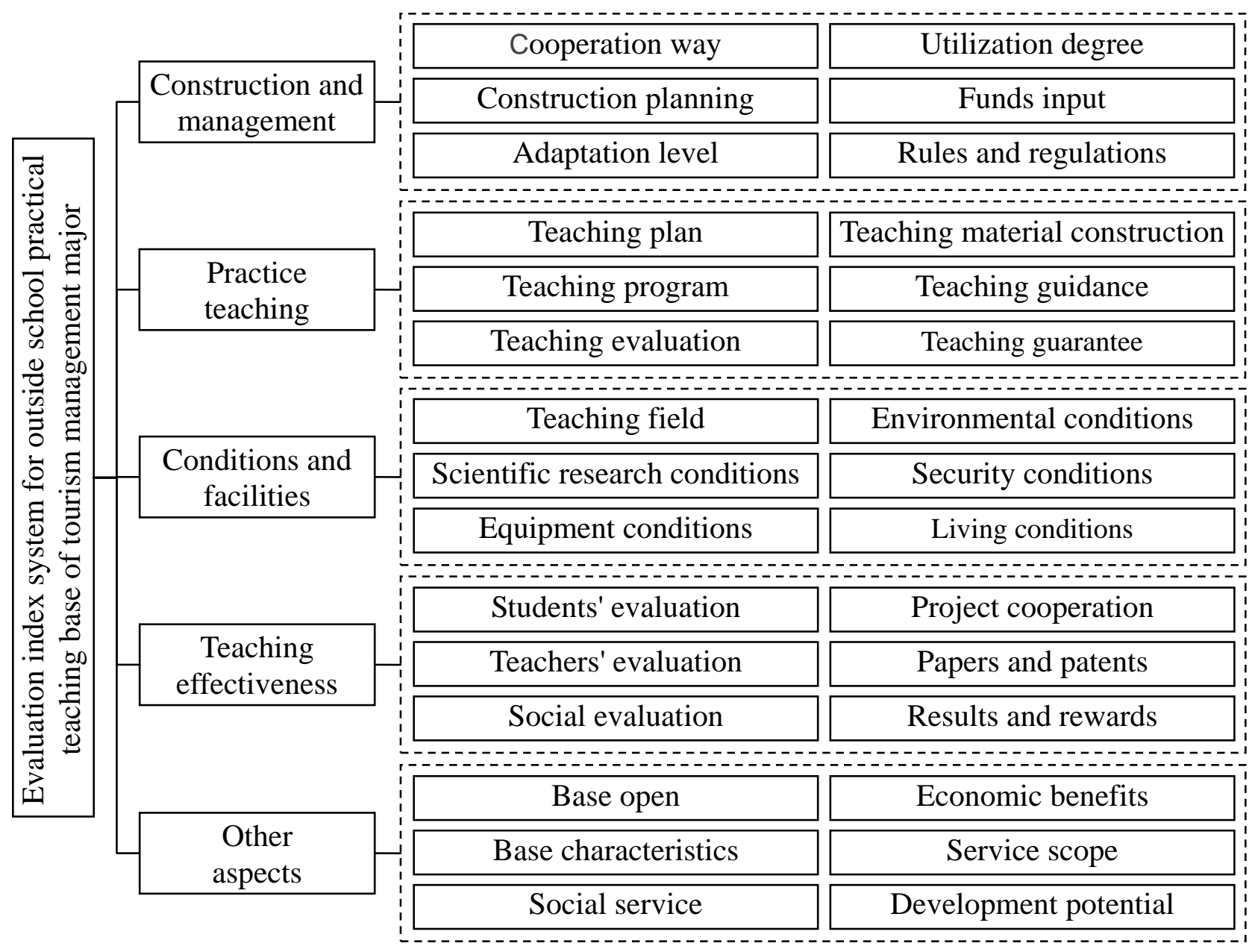

Fig.1. Structure model on Evaluation index system for outside school practical teaching base of tourism management major

(3) Conditions and facilities, including six indexes: First, Teaching field, the area, space and structure of the base are scientific and reasonable, the teaching field can meet the practical teaching of different scales and types; Second, Scientific research conditions, outside school practical teaching bases give consideration to the two major functions of teaching and research, it is necessary to provide complete scientific research conditions, assistant teachers and base staff to complete scientific research; Third, Equipment conditions, advanced equipment, various kinds, in line with the future development direction of tourism management major, network equipment , books and electronic references can meet the needs of teaching and research; Fourth, Environmental conditions, the environment directly or indirectly affects the life and development of human beings, the practical teaching field and the surrounding environment are in good condition, and the environmental protection conforms to national standards; Fifth, Security conditions, there are corresponding safety management measures and safety management rules, emergency facilities and measures are complete, and no major safety accidents have occurred since the base was used; Sixth, Living conditions, outside school practical teaching bases are generally far from the university and need to provide living conditions including accommodation, food, sports and health, in order to make practical teaching teachers and students satisfy in practical teaching.

(4) Teaching effectiveness, including six indexes: First, Students' evaluation, students are the main users of the outside school practical teaching base, students themselves evaluate their own 
teaching effects, which have definite objectivity; Second, Teachers' evaluation, teachers give the comprehensive evaluation of teaching effects can be directed to each student, but also to all students. It can be a daily performance evaluation or an examination evaluation. Third, Social evaluation, social evaluation based on employer is the most effective and direct, but also can obtain external information, analyze the school-running characteristics of the teaching base, and find problems; Fourth, Project cooperation, teachers, students or base staffs, with other departments to conduct production, learning, research cooperation projects or technological innovation activities and achieve good results; Fifth, Papers and patents, the paper is based on SCI/EI/CPCI three major searching papers, and contains Chinese social science citation index and core journal papers. The patents are mainly invention patents, and include utility model patents and design patents; Sixth, Results and rewards, the results include provincial and municipal appraisals. Rewards are based on government incentives and consider incentives from some management departments and industry associations.

(5) Other aspects, including six indexes: First, Base open, with conditions and functions open to the society, actively promote the development strategy of "bringing in and going out" education cooperation, and constantly improve the influence of the practical teaching base; Second, Base characteristics, comprehensively promote the construction of characteristic bases in different business categories and different regions, and make the characteristic bases complete and complementary as soon as possible; Third, Social service, the new model of practical teaching base with social services as the core can realize sufficient share of information and resources, improve the effect of practical teaching, and improve the quality of talents training; Fourth, Economic benefits, the practical teaching base, by serving the teaching, while opening to the society, or contracting social projects to obtain certain economic benefits to ensure the long-term development of the base; Fifth, Service scope, the teaching base should have multiple functions, opening to relevant majors in many universities, and provide practical teaching in a variety of subjects; Sixth, Development potential, with the talent advantage of colleges and universities and the financial advantages of tourism enterprises, through practical teaching and social services, etc. functions, dig the development potential of the base, and enhance the construction level of the base.

\section{Acknowledgement}

This work is supported by practical education base project for college students in Liaoning province: Outside school practical education base for tourism service in Bohai University (10167041749).

\section{References}

[1] F. L. Han, Y. Zhang, "Outside school practice: The cultivation of high employment ability of tourism management talents," Journal of Suihua University, vol. 37, no. 5, pp. 132-133, 2017.

[2] Y. Yu, "Research on practical teaching evaluation index system of outside school practice base: Taking tourism management undergraduate major as an example," Journal of Chongqing University of Education , vol. 28, no. 1, pp. 139-142, 2015.

[3] B. Gao, "Research on the construction of outside school practice teaching base for tourism management specialty," Journal of Hubei Correspondence University, vol. 28, no. 17, pp. 34-36, 2015.

[4] Y. Y. Sun, F. Teng, W. H. Lu, D. Shi, "Construction of evaluation index system for undergraduate tourism management specialty in local universities," Journal of Tonghua Normal University, vol. 38, no. 10, pp. 90-92, 2017.

[5] Z. G. Han, "Research on the evaluation system of the construction of practical teaching base in Colleges and Universities," The Science Education Article Collects, vol. 11, no. 1, pp. 3-4, 2017. 